brain tissue have been confirmed by parallel studies.

2. Bound acetylcholine and lactate dehydrogenase were similarly distributed in densitygradient separations, and were located in the regions shown previously to contain the majority of the nerve-ending particles of the homogenate. Their location was clearly different from that of succinate dehydrogenase.

3. Repeated freezing and thawing liberated slightly more and treatment of the washed particles with sucrose hypo-osmotic with respect to plasma liberated considerably more lactate dehydrogenase than acetylcholine.

4. The results support the concept that acetylcholine and lactate dehydrogenase are both contained within the same nerve-ending particles, and that there is a further barrier within these particles that provides an extra hindrance to the release of acetylcholine; this barrier may be the membrane of the synaptic vesicles.

We are grateful to Mr J. W. Boyd for carrying out the agar-gel electrophoresis and for permission to publish the results. M. K. J. thanks Miss M. A. Jefferyes for skilled technical assistance.

\section{REFERENCES}

Aldridge, W. N. \& Johnson, M. K. (1959). Biochem. J. 73, 270.

Boyd, J. W. (1962). Biochem. J. 81, 39 P.

Britten, R. J. \& Roberts, R. B. (1960). Science, 131, 32.

del Castillo, J. \& Katz, B. (1955). J. Physiol. 128, 396.

De Robertis, E., Arnaiz, G. R. de L. \& de Iraldi, A. P. (1962). Nature, Lond., 194, 794.

De Robertis, E. D. P. \& Bennett, H. S. (1955). J. biophys. biochem. Cytol. $1,47$.

De Robertis, E., de Iraldi, A. P., Arnaiz, G. R. de L. \& Salganicoff, L. (1962). J. Neurochem. 9, 23.

Gray, E. G. \& Whittaker, V. P. (1962). J. Anat., Lond., 96, 79.

Horne, R.W. \& Whittaker, V. P. (1962). Z. Zellforsch. 58, 1.

Johnson, M. K. (1960). Biochem. J. 77, 610.

Johnson, M. K. (1961). Biochem. J. 82, 281.

Johnson, M. K. (1962). Nature, Lond., 196, 1210.

Johnson, M. K. \& Whittaker, V.P.(1962). Abstr. int. Neurochem. Symp. on Enzyme Activity of the Central Nervous System. Cited in Acta neurol. scand. 38 (Suppl. 1), 60.

Michaelson, I. A. \& Whittaker, V.P. (1962). Biochem. Pharmacol. 11, 505.

Sjöstrand, F. S. (1953). J. appl. Phys. 24, 1422.

Whittaker, V.P. (1959). Biochem. J. 72, 694.

Whittaker, V.P., Michaelson, I. A. \& Kirkland, R. J. (1963). Biochem. Pharmacol. 12, 300.

Biochem. J. (1963) 88, 409

\title{
Preparation and Properties of Rat Transferrin
}

\author{
By A. H. GORDON AND L. N. LOUIS \\ National Institute for Medical Research, Mill Hill, London, N.W. 7
}

(Received 8 March 1963)

The existence of two types of transferrin in the rat has been demonstrated (Beaton, Selby \& Wright, 1961) by electrophoresis of the plasma in starch gel. Gordon (1962a) has shown that, when labelled with ${ }^{131} \mathrm{I}$ and reinjected, these two transferrins have closely similar rates of elimination. Their immunological identity has also been demonstrated (Neuhaus, Havez \& Biserte, 1962). The rat transferrin used by Gordon (1962a) for metabolic investigation was purified first by electrophoresis in a block of Pevikon C870 (see below), after which it was iodinated with ${ }^{131} \mathrm{I}$. The two transferrins with different mobilities were then separated by electrophoresis in starch gel. Further experiments showed, however, that the two types of transferrin could be separated more simply and in better yield by chromatography on diethylaminoethyl-Sephadex. The present paper describes a method of isolation in which electrophoresis in Pevikon, followed by this type of chromatography, is used. In addition some of the properties of the two types of transferrin thus prepared are reported. In the present paper these two transferrins are referred to as 'slow' and 'fast' on the basis of their electrophoretic mobility.

\section{METHODS}

Electrophoresis in Pevikon C870. The electrophoresis was carried out in general as described by Bocci (1962), by using Pevikon C870, obtained from Stockholms Superfosfat Fabriks A.-B., Stockholm, Sweden. Initially the rat serum was dialysed for at least $24 \mathrm{hr}$. against veronal buffer, $\mathrm{pH}$ 8.6 (75 mM-sodium diethylbarbiturate plus 15 mM-barbituric acid plus $5 \mathrm{~mm}-\mathrm{NaHCO}_{3}$ ). The buffer also contained sufficient $\mathrm{Fe}^{3+}$ ions to saturate all the transferrin present. The block $(30 \mathrm{~cm} . \times 17.5 \mathrm{~cm} . \times 1.5 \mathrm{~cm}$.) of Pevikon granules was made with the same buffer except that both the $5 \mathrm{~mm}$ $\mathrm{NaHCO}_{3}$ and the $\mathrm{Fe}^{3+}$ ions were omitted; $15 \mathrm{ml}$. of the dialysed serum was injected by syringe into a slit $8 \mathrm{~cm}$. from the cathodic end of the block. Sufficient cooling was obtained by using a hollow metal plate on which the block 
was placed. During the experiment tap water at approx. $15^{\circ}$ was run through the plate. Electrophoresis was carried out for $45 \mathrm{hr}$. with a current of $75 \mathrm{~mA}$. After this time a faint brown band approx. $5 \mathrm{~cm}$. wide could be seen to have migrated so that its centre was $7.5 \mathrm{~cm}$. from the origin. This band was cut away from the rest of the block and the protein eluted with $50 \mathrm{ml}$. of $0.9 \% \mathrm{NaCl}$. The filtrate thus obtained was centrifuged and the supernatant concentrated by pressure dialysis at $2^{\circ}$ against $50 \mathrm{~mm}$-tris-HCl buffer, pH 8.0.

Chromatography on diethylaminoethyl-Sephadex. Sufficient diethylaminoethyl-Sephadex A-50 (Pharmacia, Uppsala, Sweden), from which some of the fine particles had been removed by decantation after equilibration with $50 \mathrm{~mm}$-tris-HCl buffer, $\mathrm{pH} 8 \cdot 0$, was used to give a column $25 \mathrm{~cm} . \times 0.9 \mathrm{~cm}$. After dialysis against the same buffer a solution containing up to $120 \mathrm{mg}$. of the protein obtained from the Pevikon was run on to the column. Elution was then effected at room temperature by using a gradient produced with $0 \cdot 2 \mathrm{M}$-tris-HCl buffer, $\mathrm{pH} 8 \cdot 0$, and a mixing chamber of $500 \mathrm{ml}$. volume. The rate of flow was 10-12 ml./ hr. Measurements of ultraviolet absorption at $280 \mathrm{~m} \mu$ of the fractions thus obtained served to locate the bands (Fig. 1). Finally the combined fractions were concentrated by pressure dialysis at $2^{\circ}$ against water.

Analytical electrophoresis in starch gel. A starch-gel block $(25 \mathrm{~cm} . \times 15 \mathrm{~cm} . \times 0.6 \mathrm{~cm}$.) with $50 \mathrm{~mm}$-glycine- $\mathrm{NaOH}$ buffer, pH 9.0, as used by Gordon $(1962 b)$, was employed. Electrophoresis for $16 \mathrm{hr}$. at $3 \mathrm{v} / \mathrm{cm}$. gave good band separation (Fig. 2).

Determination of iron. This was carried out by the method of Ramsay (1954) after the separation of the two transferrins by chromatography. Before assay the solutions were thoroughly dialysed against iron-free water.

Amino acid analyses. These were done by the method of Moore, Spackman \& Stein (1958) with the modifications

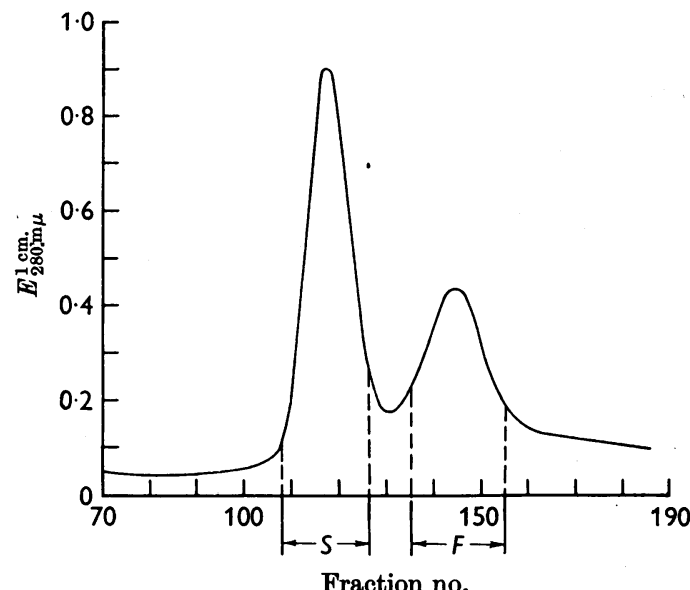

Fig. 1. Chromatography of approx. $120 \mathrm{mg}$. of transferrin concentrate obtained by preparative electrophoresis as described in the text. Elution was with a gradient of tris$\mathrm{HCl}$ buffer, $\mathrm{pH} 8.0$, from $50 \mathrm{mM}$ to $0.2 \mathrm{M}$, from a column $(25 \mathrm{~cm} . \times 0.9 \mathrm{~cm}$.$) of diethylaminoethyl-Sephadex. The$ extinction at $280 \mathrm{~m} \mu$ of $3 \cdot 1 \mathrm{ml}$. fractions was measured. $S$, 'Slow' transferrin; $F$, 'fast' transferrin. described by Jacobs (1963). The ninhydrin used was purified before use by the method of Jacobs (1956). Hydrolysis of the transferrin samples, which weighed approx. $5 \mathrm{mg}$. each, was carried out in $15 \mathrm{ml}$. of $6 \mathrm{~N}-\mathrm{HCl}$ for $24 \mathrm{hr}$. at $105^{\circ}$, nitrogen having been bubbled through the solutions before sealing off the tubes. This ratio of acid to protein was used to avoid excessive humin formation.

Determination of total nitrogen. The samples were made alkaline with dilute $\mathrm{NaOH}$ and allowed to evaporate to dryness over $\mathrm{H}_{2} \mathrm{SO}_{4}$. They were then analysed by the ninhydrin method of Jacobs (1962).

Labelling with ${ }^{59} \mathrm{Fe}$ and stability of isolated transferrin. Dissociation of iron from the transferrin was brought about by decreasing the $\mathrm{pH}$ of the solution to 4.8 by the addition of a solution of sodium acetate and EDTA. Next the excess of EDTA and the iron in complex were removed and the solution was concentrated by pressure dialysis against 10 mm-tris-HCl buffer, $\mathrm{pH} \mathrm{8 \cdot 0.} \mathrm{After} \mathrm{complete} \mathrm{removal} \mathrm{of}$ the EDTA by further dialysis against $0.1 \mathrm{M}$-tris-HCl buffer containing $\mathrm{NaHCO}_{3}(20 \mathrm{~mm})$ at the same $\mathrm{pH}$, a neutralized solution containing ${ }^{59} \mathrm{Fe}^{3+}$ ions was added. Finally an excess of $\mathrm{Fe}^{3+}$ ions was added and the solution was again dialysed against the same buffer. By this means almost all of the added radioactivity became bound to protein.

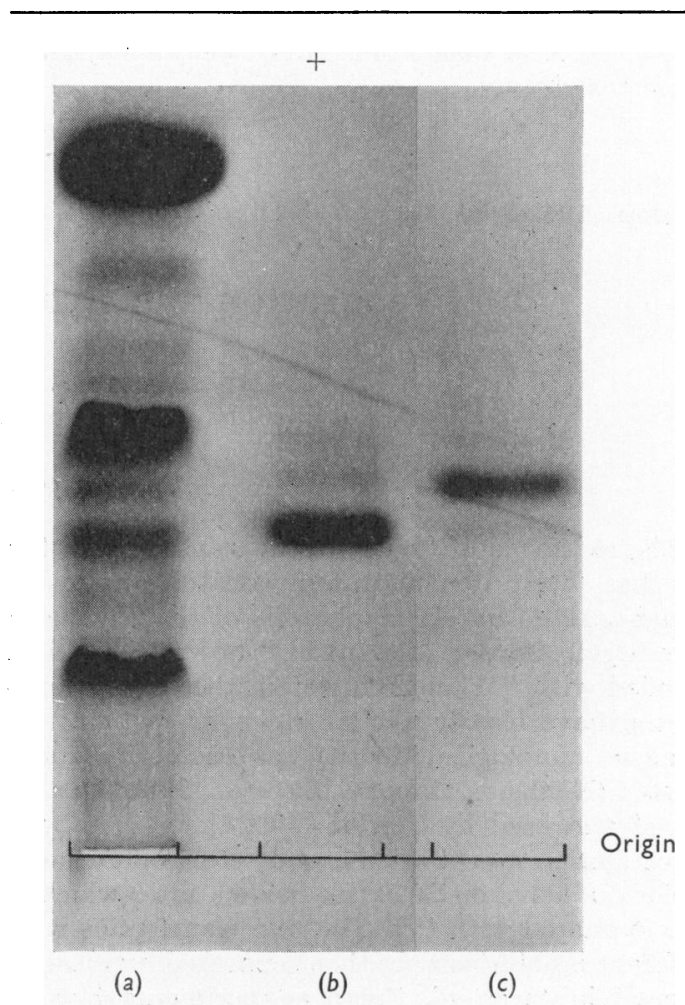

Fig. 2. Electrophoresis for $16 \mathrm{hr}$. at $3.0 \mathrm{v} / \mathrm{cm}$. in starch gel of 'fast' and 'slow' transferrins after separation by chromatography as described in the text. The gel contained $50 \mathrm{~mm}$-glycine- $\mathrm{NaOH}$ buffer, $\mathrm{pH} 9 \cdot 0$, and the electrode vessels $0 \cdot 30 \mathrm{M}$-sodium borate buffer, $\mathrm{pH} 8 \cdot 3$. (a) Rat serum; (b) 'slow' transferrin; (c) 'fast' transferrin. 
Treatment with neuraminidase. Rat plasma $(0 \cdot 1 \mathrm{ml}$.$) and$ approx. $2 \mathrm{mg}$. of the concentrate of transferrin obtained by electrophoresis in Pevikon were buffered by the addition of $0.04 \mathrm{ml}$. of $1 \mathrm{M}$-sodium acetate containing $\mathrm{CaCl}_{2}(0.4 \mathrm{M})$ to give pH 5.5. A small amount of neuraminidase, kindly supplied by Dr G. Ada, Walter and Eliza Hall Institute, Melbourne, Australia, and sufficient water were then added so that the final volume of each solution was $0 \cdot 15 \mathrm{ml}$. The solutions were then kept for $16 \mathrm{hr}$. at $37^{\circ}$. Next $4 \mu \mathrm{C}$ of ${ }^{59} \mathrm{Fe}^{3+}$ ions neutralized to $\mathrm{pH} 7$ with $0 \cdot 2 \mathrm{~N}$-ammonia in a volume of $0.3 \mathrm{ml}$. was added to each of the above solutions and to controls that were similar except for the absence of the neuraminidase. The solutions were allowed to stand for $30 \mathrm{~min}$. and were then dialysed for $16 \mathrm{hr}$. at $2^{\circ}$ against water. After centrifuging, the supernatants thus obtained were concentrated by freeze-drying and as much as possible of each was applied to a starch gel. After electrophoresis the top surface of the gel was cut off and rejected. Sections were then taken for staining with Amido Black (Fig. 3) and for radioautography. This was carried out for 16 days on an unstained section of the gel.

\section{RESULTS}

Characteristics of isolated transferrins. The degree to which the two transferrins had separated in the solution emerging from the chromatogram is shown in Fig. 1. As also shown, much the greater part of each peak was combined. The solutions thus obtained were concentrated and used for analysis.

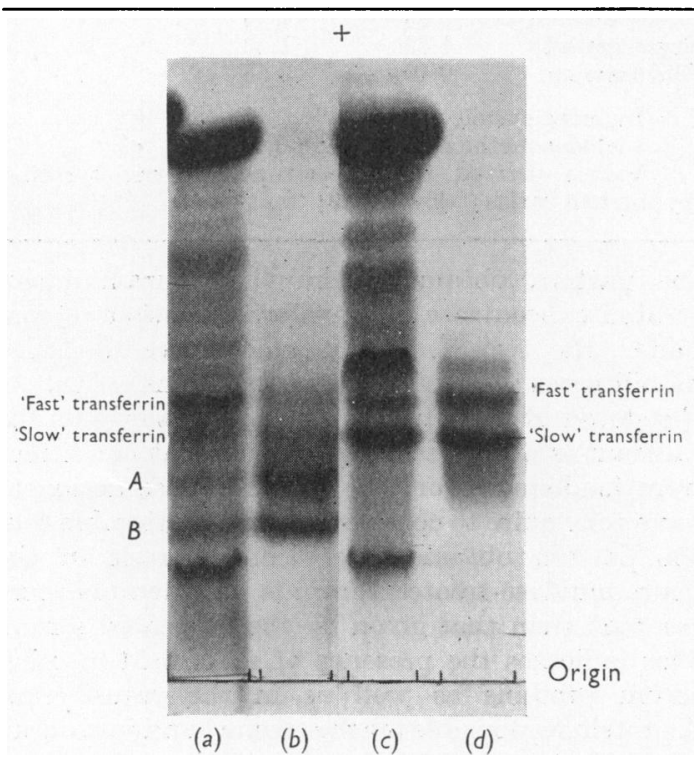

Fig. 3. Electrophoresis in starch gel of the transferrin concentrate obtained by preparative electrophoresis (as described in the text) and rat serum, before and after treatment with neuraminidase; conditions of the enzyme treatment are given in the text. (a) Rat serum + neuraminidase; (b) transferrin concentrate + neuraminidase; (c) rat serum; (d) transferrin concentrate. The electrophoresis conditions were the same as those used for the separation shown in Fig. 2.
Electrophoresis in starch gel. Some idea of the degree of purity of the two transferrins obtained from the chromatogram can be gained by reference to Fig. 2. Only very faint traces of other proteins can be detected. Mutual contamination of the two transferrins is also minimal.

Determination of molecular weight. Ultracentrifuging of the 'slow' material was kindly carried out by Dr P. A. Charlwood. A value of approx. 67000 was thus obtained (for details, see Charlwood, 1963).

Spectrophotometry. Fig. 4 shows the spectrum in the visible range given by the concentrate of transferrin obtained by the electrophoresis in Pevikon only. The presence of haem compounds seems probable since there is a peak at $412 \mathrm{~m} \mu$. This conclusion is strengthened by the fact that, after treatment with sodium dithionite at $\mathrm{pH} 9 \cdot 0$, this maximum shifted to $424 \mathrm{~m} \mu$. After separation by chromatography the spectra in the visible range of the two transferrins were found to be identical (Fig. 5). In the ultraviolet region, as shown in Table 1, $E_{281} /$ $E_{252}$ was only very slightly higher for the 'fast' as compared with the 'slow' transferrin. Attempts at reduction of the purified transferrins by treatment with sodium dithionite, sodium borohydride or hydrazine at $\mathrm{pH} \mathbf{9 \cdot 0}$ did not lead to any change in the spectrum.

Determination of iron. Duplicate determinations on 'slow' material as isolated above each showed $1 \cdot 4 \mu \mathrm{g}$. of iron $/ \mathrm{mg}$. dry wt. By assuming a binding capacity of 2 atoms of iron/molecule of transferrin of mol.wt. 67000 this represents $83 \%$ saturation with iron.

Amino acid analyses. The amounts of the various amino acids expressed both as $\mu$ moles $/ 100 \mu$ moles of total amino acids in the hydrolysates and as the numbers of residues/molecule of mol.wt. 67000 are

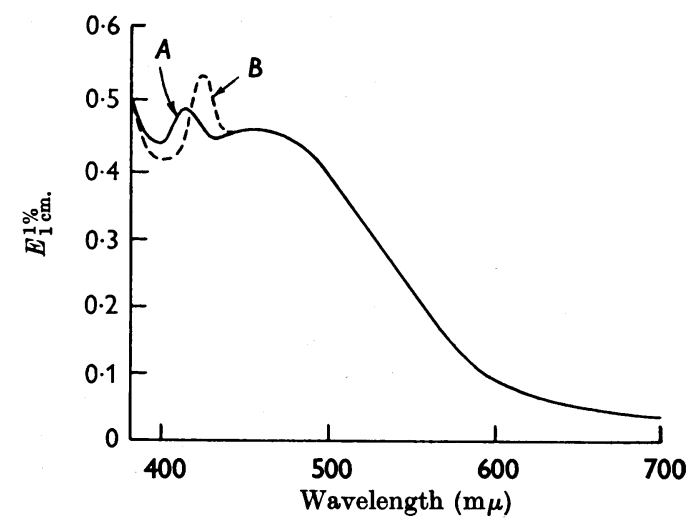

Fig. 4. Visible-light-absorption spectra of concentrate obtained by preparative electrophoresis only, as described in the text. Curve $A$ was obtained before and curve $B$ after treatment with sodium dithionite at $\mathrm{pH} 9 \cdot 0$. 


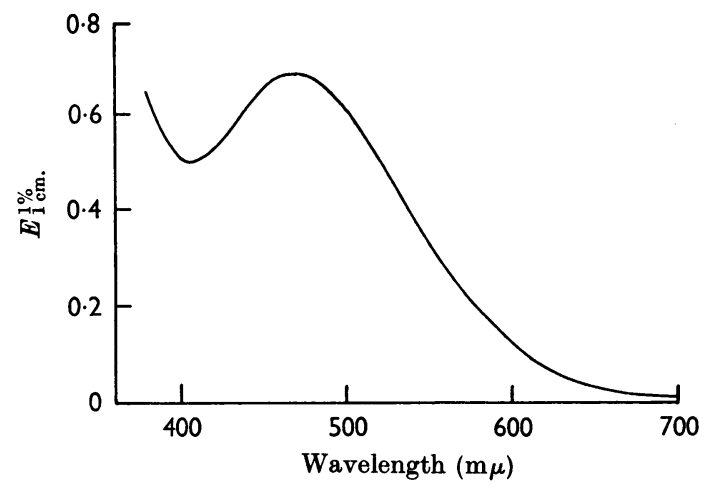

Fig. 5. Visible-light-absorption spectrum obtained from isolated 'fast' or 'slow' transferrins. The concentration is calculated from the nitrogen content of the solution of the 'slow' transferrin. The method of determination of total nitrogen is given in the text.

\section{Table 1. Light-absorption characteristics of transferrins}

The transferrins were prepared as described in the text. The ratios of the extinctions given for each transferrin are: $(a)$ in the visible region for the maximum at $465 \mathrm{~m} \mu$ divided by the minimum at $405 \mathrm{~m} \mu$ (cf. Fig. 5); (b) in the ultraviolet region for the maximum at $281 \mathrm{~m} \mu$ divided by the minimum at $252 \mathrm{~m} \mu$; (c) the maximum at $281 \mathrm{~m} \mu$ divided by the maximum at $465 \mathrm{~m} \mu$.

\begin{tabular}{|c|c|c|}
\hline & $\begin{array}{c}\text { 'Slow' } \\
\text { transferrin }\end{array}$ & $\begin{array}{l}\text { 'Fast' } \\
\text { transferrin }\end{array}$ \\
\hline $\begin{array}{ll} & E_{465}^{1 \mathrm{~cm} . ; ~} 1 \% * \\
\text { (a) } & E_{465} / E_{405} \\
\text { (b) } & E_{281} / E_{252} \\
\text { (c) } & E_{281} / E_{465}\end{array}$ & $\begin{array}{c}0 \cdot 68 \\
1 \cdot 39-1 \cdot 35 \\
1 \cdot 80 \\
23 \cdot 8\end{array}$ & $\begin{array}{l}\overline{1 \cdot 36} \\
1 \cdot 92 \\
24 \cdot 3\end{array}$ \\
\hline
\end{tabular}

* Based on the nitrogen content of the solution and $14.7 \%$ of $\mathrm{N}$ in transferrin as obtained by amino acid analysis (cf. Table 2).

given in Table 2. Since there was no significant difference between the results obtained from the two transferrins the calculation of the numbers of residues/molecule has been based on the average values for each amino acid.

Treatment with neuraminidase. The effect of neuraminidase on the mobilities in starch gel of the two transferrins was tested on the concentrate obtained by electrophoresis in Pevikon and on whole rat serum. In both cases staining of the gel revealed two new bands, $A$ and $B$ in Fig. 3, with respectively 70 and $62 \%$ of the mobilities of the 'fast' and 'slow' transferrin bands. The decreases in mobility caused by the enzyme treatment were the same for the concentrate and for the whole rat plasma. Since both solutions had been labelled with ${ }^{59} \mathrm{Fe}$ radioautography was possible. In this way confirmation was obtained that the materials forming both of the new bands are able to bind iron. Fig. 3 shows that

\section{Table 2. Amino acid composition of transferrins}

The transferrins were prepared as described in the text. The amino acid composition expressed in terms of $\mu$ moles/ $100 \mu$ moles of total amino acids does not include any contribution from ammonia. The amino acid composition expressed in terms of residues/molecule is calculated from the average value for $\mu$ moles $/ 100 \mu$ moles of total amino acids in 'slow' and 'fast' transferrins, and is based on a mol.wt. of 67000.

\begin{tabular}{|c|c|c|c|}
\hline & \multicolumn{3}{|c|}{ Amino acid composition } \\
\hline & \multicolumn{2}{|c|}{$\begin{array}{c}(\mu \text { moles } / 100 \mu \text { moles of } \\
\text { total amino acids })\end{array}$} & \multirow[b]{2}{*}{$\begin{array}{l}\text { (residues/ } \\
\text { molecule) }\end{array}$} \\
\hline & $\begin{array}{c}\text { 'Slow' } \\
\text { transferrin }\end{array}$ & $\begin{array}{c}\text { 'Fast' } \\
\text { transferrin }\end{array}$ & \\
\hline Lysine & $8 \cdot 22$ & $8 \cdot 21$ & 50 \\
\hline Histidine & $2 \cdot 61$ & $2 \cdot 67$ & 15 \\
\hline Arginine & $3 \cdot 60$ & $3 \cdot 87$ & 23 \\
\hline Aspartic acid & $10 \cdot 73$ & $10 \cdot 57$ & 65 \\
\hline Threonine & $5 \cdot 56$ & $5 \cdot 60$ & 34 \\
\hline Serine & $6 \cdot 23$ & $6 \cdot 54$ & 39 \\
\hline Glutamic acid & $8 \cdot 87$ & $8 \cdot 85$ & 54 \\
\hline Proline & $5 \cdot 20$ & $5 \cdot 48$ & 33 \\
\hline Glycine & $8 \cdot 80$ & $8 \cdot 41$ & 53 \\
\hline Alanine & $8 \cdot 38$ & $8 \cdot 30$ & 51 \\
\hline Cystine (half)* & $2 \cdot 65$ & $2 \cdot 38$ & 15 \\
\hline Valine & $5 \cdot 72$ & 5.98 & 36 \\
\hline Methionine $†$ & $0 \cdot 68$ & 0.68 & 4 \\
\hline Isoleucine & $3 \cdot 12$ & $3 \cdot 21$ & 19 \\
\hline Leucine & $9 \cdot 00$ & $9 \cdot 01$ & 55 \\
\hline Tyrosine & $3 \cdot 03$ & $3 \cdot 25$ & 19 \\
\hline Phenylalanine & $5 \cdot 03$ & 4.98 & 31 \\
\hline Tryptophan $\ddagger$ & $1 \cdot 32$ & $1 \cdot 42$ & 8 \\
\hline Glucosamine & $0 \cdot 40$ & 0.53 & 3 \\
\hline \multicolumn{4}{|c|}{$\begin{array}{l}\text { * Includes cysteic acid. } \\
\text { † Includes methionine sulphoxide. } \\
\text { † Values derived from spectrophotometric tyrosine } \\
\text { tryptophan ratios ('slow', 2.29; 'fast', } 2 \cdot 3 \text { ). }\end{array}$} \\
\hline
\end{tabular}

the pattern obtained from the neuraminidasetreated concentrate of transferrin consists of four bands, the two weaker of which have the same mobilities as those of the untreated transferrins. As the slower of these bands showed up faintly on the radioautograph it seems probable that conditions were inadequate for the neuraminidase action to have gone quite to completion. It is noticeable that the pattern obtained by electrophoresis of the neuraminidase-treated serum is considerably more complex than that given by the untreated serum. This indicates the presence of sialic acid in other serum proteins as well as in the transferrins. A protein responsible for the strong band just ahead of the 'fast' transferrin is particularly noticeable in this respect.

\section{DISCUSSION}

Especially since the discovery by Smithies (1957) that the transferrins are a group of genetically determined plasma proteins there have been many investigations of the electrophoretic properties of these substances. Other aspects of their properties 
have been less thoroughly studied, owing partly to the rather large volumes of serum required for isolation, at least by the original methods (Laurell, 1953; Schultze, Heide \& Müller, 1957).

Because it seemed possible that the usually quoted value of 90000 for the mol.wt. of human transferrin might require revision, this protein was isolated by the present method. In addition, the transferrin from the rhesus monkey (Macacus rhesus) was also isolated. Ultracentrifugal studies on the human, monkey and rat transferrins thus obtained are reported by Charlwood (1963). The value of approx. 67000 thus obtained for the mol. wt. of the rat transferrin has been used in the calculation of the numbers of amino acid residues/ molecule that are shown in Table 2.

Quantitative amino acid analyses of human and monkey (Cynomolgus) transferrins have been reported by Parker \& Bearn (1962). Conversion of their values of $\mu$ moles of each amino acid found for $1.596 \mathrm{mg}$. of human transferrin into percentages of the total present allows comparison with the present values for rat transferrin. Such a comparison shows that, with the exception of cystine and methionine, the proportions of the various amino acids in the two proteins are close although the differences are too large to be due only to analytical error. The proportions of both cystine and methionine, on the other hand, are approximately double in the human as compared with those in rat transferrin. Direct comparison with the numbers of residues of the amino acids reported as being present in human transferrin by Parker \& Bearn (1962) are not valid because the numbers given are calculated on the basis of the mol.wt. 90000 (cf. Charlwood, 1963).

Assuming that the total iron-binding capacity of rat serum is $530-610 \mu \mathrm{g}$. of iron/100 ml. (Itzhaki \& Belcher, 1961) the present method permits the isolation of about one-half of the total transferrin originally present. It is relatively simple, and does not involve the use of organic solvents or any considerable changes in $\mathrm{pH}$, and yields the individual transferrins free from other serum proteins and nearly completely separated from one another, at least as judged by the results of electrophoresis in starch gel (Fig. 2). The 'slow' transferrin also appeared to be homogeneous when subjected to ultracentrifuging (Charlwood, 1963). Further, when a mixture of the 'slow' and the 'fast' transferrins was similarly treated no signs of separation could be detected.

The unsuccessful attempts by Fraenkel-Conrat (1950) to ascertain the nature of the iron-binding group in human transferrin serve to show that this property depends on a number of different structural features of the molecule (Fraenkel-Conrat \& Feeney, 1950). Thus it was found that substitution of amino, phenolic or amide groups led to diminished iron-binding capacity. In the present work with rat transferrin the ease with which the protein could become partially denatured became evident when it was found that considerable changes in the spectrum in the visible range were brought about by removal of the iron at $\mathrm{pH} 4.8$ and its reintroduction after the $\mathrm{pH}$ had been returned to neutrality. On the other hand, the present rat transferrin and human transferrin obtained by the same procedure were unaffected by treatment at $\mathrm{pH} 9$ with sodium dithionite.

This finding differs from that of Koechlin (1952), who found that human transferrin obtained by fractionation with ethanol could be reduced with sodium dithionite. The $E_{\mathbf{4 6 5}} / E_{405}$ ratio of the rat transferrin isolated as described above is $1 \cdot 35-1 \cdot 39$, which is almost identical with the same ratio obtained by Laurell (1953) for pig transferrin (1.40 1.41) after four or five recrystallizations. Laurell (1953) has stressed that preparations of transferrin for which this ratio is lower are likely to be contaminated with traces of haem proteins very similar electrophoretically to transferrin. Although such compounds must certainly have been present in the crude transferrin fraction obtained by the electrophoresis in Pevikon (Fig. 4) they appear to separate quantitatively from the transferrins during the chromatography on diethylaminoethyl-Sephadex. The persistence of traces of such material in the 'fast' transferrin isolated by electrophoresis in starch gel (Gordon, 1962a) must be presumed. The observed colour differences led to the use of the names 'brown' and 'pink' transferrin for the two forms.

The present work has not revealed any reason for the electrophoretic-mobility difference shown by the two types of rat transferrin. Since the mobilities of both types are equally affected after treatment with neuraminidase it seems unlikely that the content of sialic acid is the responsible factor. A rather similar situation has been reported for the human transferrins by Parker \& Bearn (1962).

\section{SUMMARY}

1. A method for the isolation of transferrin from rat serum depending only on electrophoresis and ion-exchange chromatography is described.

2. The two types of transferrin present in the serum are separable not only by electrophoresis in starch gel but also by chromatography on diethylaminoethyl-Sephadex. After the removal of sialic acid with neuraminidase the mobility difference is retained.

3. Results on the molecular weights, absorption spectra, iron contents and amino acid compositions of the two proteins are given. 
We are grateful to Dr S. Jacobs for carrying out the amino acid analyses, and to Dr G. Beaven and Miss E. Bailey for the spectrophotometric measurements.

\section{REFERENCES}

Beaton, G. H., Selby, A. E. \& Wright, A. M: (1961). J. biol. Chem. 236, 2001.

Bocci, V. (1962). J. Chromat. 8, 218.

Charlwood, P. A. (1963). Biochem. J. 88, 394.

Fraenkel-Conrat, H. (1950). Arch. Biochem. 28, 452.

Fraenkel-Conrat, H. \& Feeney, R. E. (1950). Arch. Biochem. 29, 101.

Gordon, A. H. (1962a). Proc. 10th Colloq. Protides in Biological Fluids, Bruges, p. 71.

Gordon, A. H. (1962b). Biochem. J. 82, 531.
Itzhaki, R. F. \& Belcher, E. H. (1961). Arch. Biochem. Biophys. 92, 74.

Jacobs, S. (1956). Analyst, 81, 502.

Jacobs, S. (1962). Analyst, 87, 53.

Jacobs, S. (1963). Biochem. J. 87, 30 P.

Koechlin, B. A. (1952). J. Amer. chem. Soc. 74, 2649.

Laurell, C. B. (1953). Acta chem. scand. 7, 1407.

Moore, S., Spackman, D. H. \& Stein, W. H. (1958). Analyt. Chem. 30, 1185.

Neuhaus, O. W., Havez, R. \& Biserte, G. (1962). C.R. Soc. Biol., Paris, 161, 1105.

Parker, C. W. \& Bearn, A. G. (1962). J. exp. Med. 115, 83.

Ramsay, W. N. M. (1954). Biochem. J. 57, xvii.

Schultze, H. E., Heide, K. \& Müller, H. (1957). Behringwerk-Mitteilungen, 32, 25.

Smithies, O. (1957). Nature, Lond., 180, 1482.

Biochem. J. (1963) 88. 414

\title{
On the Mechanism of Action of Phospholipase A
}

\author{
By R. M. C. DAWSON \\ Biochemistry Department, Agricultural Research Council Institute of Animal Physiology, \\ Babraham, Cambridge
}

(Received 4 February 1963)

The phospholipase A (phosphatide acyl-hydrolase, EC 3.1.1.4) of snake venom catalyses the hydrolyses of diacylated nitrogen-containing phosphoglycerides with the liberation of a single fatty acid and the formation of the corresponding lysophosphoglyceride. Both phosphatidylethanolamine and phosphatidylserine are attacked as well as lecithin and with all substrates only the fatty acid esterified on the $\beta$-position is released (Marinetti, Erbland \& Stotz, 1958; Tattrie, 1959; Hanahan, Brockerhoff \& Barron, 1960 ; de Haas \& van Deenen, 1961).

It has recently been shown that with two other phospholipases the rate of reaction is appreciably influenced by the electrokinetic state of the enzyme and its substrate. Thus a phospholipase preparation isolated from Penicillium notatum splits lecithin only when the substrate micelles have a net negative $\zeta$ potential (Bangham \& Dawson, 1959). On the other hand, the phospholipase $\mathrm{C}$ of Clostridium perfringens only works when the enzyme possesses a net negative charge, and the substrate contains excess of positive groupings on its surface (Bangham \& Dawson, 1962). In the present work, similar physicochemical investigations have been made on the phospholipase A of snake venom, the aqueous reaction mixture recently devised by Magee \& Thompson (1960) being used. While no evidence has been obtained that the initial reaction is controlled by the net $\zeta$ potential of the substrate, it has been shown that many anionic amphipathic molecules, including the fatty acid produced in the reaction, are inhibitory. The stimulatory effect of ether when the enzyme is attacking lecithin is probably due to a surface dilution of the closely packed molecules orientated at the lipid-water interface and a removal of inhibiting fatty acid carboxyl groups from the interface. A preliminary account of this work has been published (Dawson, 1962).

\section{EXPERIMENTAL}

Preparation of purified enzyme. Venom of the cobra (Naja naja) was used as a source of phospholipase A. After collection at London Zoo, it was air-dried at a slightly elevated temperature and subsequently kept for a period of 2 years in a desiccator over $\mathrm{CaCl}_{2}$ at room temperature. The crude venom was directly fractionated in a density-gradient electrophoresis apparatus (LKB Stockholm) according to the techniques of Svensson (1960). The density gradient was prepared by using $0.01 \mathrm{M}$-sodium acetate-acetic acid buffer, pH $5 \cdot 1$, as the light component and the same buffer containing $45 \%$ (by vol.) of glycerol as the heavy component. About $20 \mathrm{mg}$. of cobra venom was dissolved in $5 \mathrm{ml}$. of heavy buffer and the density adjusted by adding light buffer so that it just floated on the heavy buffer. This enzyme solution was layered on to the heavy buffer contained in the electrophoresis column; the gradient was then built up, starting with a 'light-heavy' buffer containing $40 \%$ of glycerol. The electrophoresis was carried out for 16-18 hr. $(900 \mathrm{v}, 8 \mathrm{~mA})$ at a temperature of running tap water $\left(10-14^{\circ}\right)$. Fractions from the column were obtained 